\section{Kidney \\ Blood Pressure Research}

Kidney Blood Press Res 2012;36:131-138

\begin{tabular}{l|l}
\hline DOI: $10.1159 / 000341491$ & (c) 2012 S. Karger AG, Basel
\end{tabular}

www.karger.com/kbr

$1420-4096 / 12 / 0361-0131 \$ 38.00 / 0$

\title{
Effects of Carvedilol as Third-Line Add-On Therapy on Blood Pressure and Glucose Metabolism in Type 2 Diabetic Patients with Chronic Renal Disease Stage 3 and Above
}

\author{
Gen Yasuda Keisuke Yatsu Yuichiro Yamamoto Nobuhito Hirawa \\ Division of Nephrology and Hypertension, Center Hospital, Yokohama City University School of Medicine, \\ Yokohama, Japan
}

\section{Key Words}

$\beta$-Blocker • Hypertension • Diabetic nephropathy $\bullet$ Chronic kidney disease $\bullet$ Carvedilol

\begin{abstract}
Background: We evaluated the effect of coadministration of $\beta$-blocker (carvedilol) as the third agent with angiotensin II receptor blockers (ARB) and calcium channel blockers (CCB) on blood pressure (BP) regulation and glucose metabolism. Methods: Diabetic patients who did not achieve the therapeutic BP goal $(140 / 90 \mathrm{mmHg})$ by ARB and CCB combination therapy were recruited. This study was designed to compare the $B P$ regulating effects by adding carvedilol (10 mg/day, $n=30)$ and by doubling the dose of either ARB $(n=34)$ or CCB $(n=31)$. Serum glucose metabolism was examined. Results: The carvedilol group showed a decrease $(P<0.01)$ in BP from $166 \pm 11 / 90 \pm 8$ to $156 \pm 9 / 84 \pm 7 \mathrm{mmHg}$ at 12 weeks. In the ARB and CCB groups, BP also decreased $(P<0.01)$ from $164 \pm 11 / 87 \pm 8$ to $153 \pm 10 / 83 \pm 8$ and $163 \pm 7 / 87 \pm 8$ to $153 \pm 8 / 84 \pm 9$ $\mathrm{mmHg}$ at 12 weeks. The rates of achieving therapeutic goal at 12 weeks were $36.7 \%$ in the carvedilol, $38.2 \%$ in the ARB and $41.9 \%$ in the CCB group. Serum glucose metabolism did not change in all groups. Conclusions: These results suggest that adding carvedilol decreased BP as safely as increasing the dose of ARB or CCB in patients with diabetic nephropathy.
\end{abstract}




\section{Kidney Blood Pressure Research}

Kidney Blood Press Res 2012;36:131-138

\begin{tabular}{l|l}
\hline DOI: 10.1159/000341491 & (C) 2012 S. Karger AG, Basel
\end{tabular}

Published online: October 23, 2012

www.karger.com/kbr

Yasuda/Yatsu/Yamamoto/Hirawa: Effects of Carvedilol as Third-Line Add-On Therapy on Blood Pressure in Diabetic Patients

\section{Introduction}

In patients with overt diabetic nephropathy, blood pressure (BP) control is of utmost importance to retard the aggravation of renal insufficiency. Currently guidelines $[1,2]$ recommend controlling BP levels to lower than $130 / 80 \mathrm{mmHg}$ in such patients. However, some clinical trials recently documented that only $30-50 \%$ of patients with hypertension actually achieved a blood pressure goal of $<140 / 90 \mathrm{~mm} \mathrm{Hg}$ [3]. Patients with multiple organ damages usually have hypertension that is difficult to control. In such cases, the use of a single antihypertensive agent is insufficient to lower BP. Thus, the latest British Hypertension Society [1] and European Society of Hypertension guidelines [2] indicate that renin-angiotensin system (RAS) inhibitors, such as angiotensin II receptor blockers (ARB) and angiotensin-converting enzyme inhibitors, are the first-line agents to reduce BP and the rate of decline in renal function. As second-line agents, calcium channel blockers (CCB) are widely used for the prevention of organ damage. If a combination of the two at the usual doses is ineffective, increasing the dose of either RAS inhibitors or CCB to the maximum dose may be the next option. However, renal insufficiency increases the risk of adverse drug reactions by dose elevation. Therefore, adding thiazides is suitable as a third-line agent as far as renal function remains mildly impaired [chronic kidney disease (CKD) stage 3 or below].

If patients have more advanced renal insufficiency, adding another class of medication would be an alternative strategy, although the guidelines do not indicate clearly the third choice for uncontrolled hypertension. In these patients, $\beta$-blockers seem to be more effective than increasing the dose of either RAS inhibitors or CCB.

Recently the third generation $\beta$-blocker, carvedilol, has been reported to possess characteristics different from the previously available non-selective and $\beta_{1}$ selective-blockers that have adverse effects on glucose and lipid metabolism $[4,5]$. Nevertheless, little is known about the effects of coadministration of carvedilol as the third agent with a combination of RAS inhibitors and CCB on BP regulation and glucose metabolism. The present study was designed to examine the safety and efficacy of adding carvedilol on BP control in patients with advanced diabetic nephropathy already treated with ARB and CCB.

\section{Subjects and Methods}

\section{Patients}

Type 2 diabetic patients with hypertension and advanced renal failure (CKD stage 3 or above, aged over 40 years), who had been treated with CCB and ARB at half of the maximum recommended doses for 12 week or longer were enrolled in the study. Diabetic nephropathy was diagnosed if albuminuria (>300 mg/g creatinine) persisted without clinical or laboratory evidence of renal disease other than diabetic glomerulosclerosis. Excluded were patients who had a history of cardiac, hematological or hepatic disease; solitary kidney; hormone-induced hypertension; cerebral infarction or hemorrhage; or other major diseases. Patients who had bilateral contracted kidneys observed on kidney ultrasonography or computed tomography were also eliminated, because of the possibility of having renovascular hypertension. The criteria for inclusion in this study were a systolic BP higher than $140 \mathrm{~mm} \mathrm{Hg}$ and a diastolic BP between 90 and $110 \mathrm{~mm} \mathrm{Hg}$ (Korotkov phase V) measured on at least three separate occasions after receiving ARB and CCB combination therapy at half the maximum recommended doses for 12 weeks or longer. Patients with a diastolic BP of $>110 \mathrm{~mm} \mathrm{Hg}$ were excluded. Informed consent for participation in the study was obtained from each subject. The protocol was approved by the Ethical Committee of Yokohama City University Hospital.

\section{Protocol}

The patients who fulfilled the criteria were allocated into three groups by random assignments generated by the computer. The carvedilol group was assigned to receive $10 \mathrm{mg} /$ day of carvedilol in 


\section{Kidney Blood Pressure Research}

Kidney Blood Press Res 2012;36:131-138

\begin{tabular}{l|l}
\hline DOI: $10.1159 / 000341491$ & (c) 2012 S. Karger AG, Basel
\end{tabular}

Published online: October 23, 2012

www.karger.com/kbr

Yasuda/Yatsu/Yamamoto/Hirawa: Effects of Carvedilol as Third-Line Add-On Therapy on Blood Pressure in Diabetic Patients

addition to ARB and CCB combination therapy at unchanged doses. The ARB group was assigned to receive the maximum dose of ARB combined with unchanged dose of CCB. The CCB group was assigned to double dose (maximum dose) of CCB combined with unchanged dose of ARB. During 12-week treatment with these drugs, the patients were not prescribed any other antihypertensive drug. Patients in the three groups who did not achieve BP goal (systolic BP below130 mmHg and diastolic BP below $80 \mathrm{mmHg}$ ) after 12 weeks of the study treatment received furosemide (20-40 mg daily) during the next 12 weeks. Patients who achieved the BP goal continued the treatment regimens without change. When the BP goal was still not reached at the end of 24 weeks, patients received other lines of antihypertensive agents for another 24 weeks. All patients were asked to maintain a diet containing $5 \mathrm{~g} \mathrm{NaCl}, 0.6 \mathrm{~g} / \mathrm{kg}$ protein, and $1,800 \mathrm{mg}$ potassium daily.

\section{Blood pressure measurement}

Office systolic and diastolic BP were measured every four weeks with the patient in a sitting position after five minutes of rest. Each BP measurement was determined using a sphygmomanometer, and the average of two measurements was calculated.

Blood glucose and homeostasis model assessment-insulin resistance

Blood samples were obtained for glucose metabolism at 0, 4, 12, 24, and 48 weeks. Samples were analyzed with an autoanalyzer (Hitachi 7250, Hitachi, Tokyo, Japan). Homeostasis model assessmentinsulin resistance (HOMA-IR) as a validated clinical index of insulin resistance [6] was determined by the following formula:

HOMA-IR = fasting serum glucose level $(\mathrm{mg} / \mathrm{dL}) \times$ fasting serum insulin concentration $(\mu \mathrm{U} / \mathrm{mL}) / 405$

\section{Renal Function}

Urinary samples were collected at approximately the same time when blood samples were obtained. Urinary albumin excretion was expressed as a ratio to urinary creatinine concentrations. Estimated glomerular filtration rate (eGFR) as an index of renal function was calculated by the following formula [7]:

eGFR $\left(\mathrm{mL} / \mathrm{min} / 1.73 \mathrm{~m}^{2}\right)=194 \times$ creatinine $^{-1.094} \times$ age $^{-0.287}(\times 0.739$, if female $)$

\section{Statistical Analysis}

All values are expressed as mean \pm SD. The changes in parameters throughout treatment in each group were analyzed by using Dunnet's test for multiple comparisons. Multiple comparisons at the baseline values were analyzed by using Bonferroni's test. Categorical variables were analyzed by $\chi^{2}$ test or Kruskal-Wallis test. A $p$ value less than 0.05 were considered statistically significant.

\section{Results}

\section{Clinical Characteristics}

Ninety-eight type 2 diabetic patients with advanced renal failure and hypertension, ranging in age from 46 to 78 years, participated in the study. The mean duration of clinically observed diabetes was 16.2 years. Three patients were excluded due to noncompliance. The final analysis was conducted on 30 patients in the carvedilol group, 34 patients in the ARB group, and 31 patients in the CCB group (total 95 patients). Table 1 summarizes the baseline characteristics of the three groups, and the ARB and CCB that the patients were taking at half the maximum doses before the study was initiated. There were no differences in all baseline parameters among three groups.

\section{Blood Pressure}

Baseline BP were not different among three groups (Table 2). Systolic and diastolic BP of patients in the three groups decreased significantly at 12 weeks except diastolic BP in the CCB group (Table 2). Eleven patients (36.7\%) in the carvedilol group had BP controlled at below the therapeutic goal of systolic BP $130 \mathrm{mmHg}$ and diastolic BP $80 \mathrm{mmHg}$ at 12 weeks, and 12 patients (40.1\%) achieved the goal at 24 weeks with furosemide. Eventually, $11(36.7 \%)$ patients achieved the therapeutic BP goal at 48 weeks. 


\section{Kidney \\ Blood Pressure Research}

Yasuda/Yatsu/Yamamoto/Hirawa: Effects of Carvedilol as Third-Line Add-On Therapy on Blood Pressure in Diabetic Patients

Table 1: Patient background and anti-hypertensive agents taken at the start of the study

\begin{tabular}{|c|c|c|c|c|}
\hline \multirow[b]{2}{*}{ Variable } & \multicolumn{3}{|c|}{ Group } & \multirow[b]{2}{*}{$P$} \\
\hline & $\begin{array}{c}\text { Carvedilol } \\
(\mathrm{n}=30)\end{array}$ & $\begin{array}{c}\text { ARB } \\
(\mathrm{n}=34)\end{array}$ & $\begin{array}{c}\mathrm{CCB} \\
(\mathrm{n}=31)\end{array}$ & \\
\hline Age (Years) & $63 \pm 9$ & $62 \pm 10$ & $63 \pm 10$ & 0.825 \\
\hline Men: women & $14: 16$ & 19:15 & $18: 13$ & 0.504 \\
\hline Weight (Kg) & $61.4 \pm 8.6$ & $62.7 \pm 8.9$ & $61.6 \pm 8.4$ & 0.973 \\
\hline Body mass index $\left(\mathrm{kg} / \mathrm{m}^{2}\right)$ & $23.4 \pm 2.9$ & $23.2 \pm 3.1$ & $23.4 \pm 2.9$ & 0.661 \\
\hline Angiotensin II receptor blockers & & & & 0.915 \\
\hline Losartan & 10 & 8 & 10 & \\
\hline Olmesartan & 6 & 10 & 6 & \\
\hline Telmisartan & 7 & 9 & 6 & \\
\hline Valsartan & 7 & 7 & 9 & \\
\hline Calcium channel blockers & & & & 0.561 \\
\hline Amlodipine & 9 & 13 & 12 & \\
\hline Azelnidipine & 6 & 8 & 8 & \\
\hline Benidipine & 8 & 5 & 4 & \\
\hline Cilnidipine & 3 & 4 & 1 & \\
\hline Efonidipine & 4 & 4 & 6 & \\
\hline
\end{tabular}

Data are expressed as mean \pm S.D. or number of patients. ARB; angiotensin II receptor blockers, CCB; calcium channel blockers

Table 2: Systolic and diastolic blood pressures and heart rates during treatment for 48 weeks in three group

\begin{tabular}{|c|c|c|c|c|c|c|}
\hline \multirow{2}{*}{ Parameter } & \multirow{2}{*}{ Group } & \multicolumn{5}{|c|}{ Duration of treatment (weeks) } \\
\hline & & 0 & 4 & 12 & 24 & 48 \\
\hline \multicolumn{7}{|c|}{ Systolic blood pressure (mmHg) } \\
\hline & Carvedilol & $166 \pm 11$ & $160 \pm 13$ & $156 \pm 9^{*}$ & $154 \pm 12^{* *}$ & $154 \pm 14^{* *}$ \\
\hline & $\mathrm{ARB}$ & $164 \pm 11$ & $155 \pm 13$ & $153 \pm 10^{* *}$ & $153 \pm 13^{* *}$ & $152 \pm 13^{* *}$ \\
\hline & CCB & $163 \pm 7$ & $152 \pm 12^{* *}$ & $153 \pm 8^{* *}$ & $153 \pm 9^{* *}$ & $152 \pm 9^{* *}$ \\
\hline & $\mathrm{P}^{\dagger}$ & 0.572 & & & & \\
\hline \multicolumn{7}{|c|}{ Diastolic blood pressure (mmHg) } \\
\hline & Carvedilol & $90 \pm 8$ & $86 \pm 8^{* *}$ & $84 \pm 7^{* *}$ & $83 \pm 8^{* *}$ & $83 \pm 7^{* *}$ \\
\hline & ARB & $87 \pm 8$ & $83 \pm 10$ & $83 \pm 8^{*}$ & $83 \pm 9$ & $81 \pm 8^{* *}$ \\
\hline & CCB & $87 \pm 8$ & $83 \pm 7^{* *}$ & $84 \pm 9$ & $80 \pm 7^{* *}$ & $80 \pm 11^{* *}$ \\
\hline & $\mathrm{P}^{\dagger}$ & 0.389 & & & & \\
\hline \multicolumn{7}{|c|}{ Heart rate (beat/minute) } \\
\hline & Carvedilol & $73 \pm 9$ & $73 \pm 9$ & $72 \pm 9$ & $72 \pm 9$ & $73 \pm 8$ \\
\hline & ARB & $73 \pm 10$ & $70 \pm 10$ & $70 \pm 9$ & $73 \pm 9$ & $72 \pm 8$ \\
\hline & CCB & $73 \pm 7$ & $72 \pm 9$ & $74 \pm 8$ & $69 \pm 9$ & $71 \pm 10$ \\
\hline & $\mathrm{P}^{\dagger}$ & 0.995 & & & & \\
\hline
\end{tabular}

Thirteen patients $(38.2 \%)$ in the ARB group reached the therapeutic goal set in this study during the first 12 weeks. By adding furosemide, 11 patients $(32.3 \%)$ achieved the BP goal at 24 weeks. Finally 13 patients (38.2\%) fulfilled the BP goal at 48 weeks.

Thirteen patients (41.9\%) in the CCB group reached the therapeutic goal during the first 12 weeks, and 19 patients (61.3\%) at 24 weeks with furosemide. At 48 weeks, 15 patients (48.4\%) fulfilled the target BP.

At 48 weeks, the number of other classes of antihypertensive drugs administered in order to achieve the $\mathrm{BP}$ goal was $4.0 \pm 0.9$ in the carvedilol group, which was higher $(\mathrm{P}=0.001)$ than $3.0 \pm 0.9$ in the ARB group and $3.1 \pm 0.9$ in the CCB group.

\section{Renal Function}

Baseline renal function indices were not different among the three groups (Table 3). During 12 weeks of therapy, the ARB group showed a significant decrease in eGFR and 


\section{Kidney \\ Blood Pressure Research}

Yasuda/Yatsu/Yamamoto/Hirawa: Effects of Carvedilol as Third-Line Add-On Therapy on Blood Pressure in Diabetic Patients

Table 3: Renal function during treatment for 48 weeks in each group

\begin{tabular}{|c|c|c|c|c|c|c|}
\hline \multirow{2}{*}{ Parameter } & \multirow{2}{*}{ Group } & \multicolumn{5}{|c|}{ Duration of treatment (weeks) } \\
\hline & & 0 & 4 & 12 & 24 & 48 \\
\hline \multirow{4}{*}{$\begin{array}{l}\text { Serum potassium } \\
\text { concentration } \\
(\mathrm{mmol} / \mathrm{L})\end{array}$} & Carvedilol & $4.4 \pm 0.5$ & $4.5 \pm 0.4$ & $4.5 \pm 0.4$ & $4.6 \pm 0.5$ & $4.7 \pm 0.4^{*}$ \\
\hline & $\mathrm{ARB}$ & $4.4 \pm 0.5$ & $4.7 \pm 0.5^{*}$ & $4.7 \pm 0.6^{*}$ & $4.8 \pm 0.5^{* *}$ & $4.8 \pm 0.6^{* *}$ \\
\hline & $\mathrm{CCB}$ & $4.3 \pm 0.6$ & $4.6 \pm 0.5$ & $4.6 \pm 0.4$ & $4.7 \pm 0.5$ & $4.7 \pm 0.5^{*}$ \\
\hline & $\mathrm{P}^{\dagger}$ & 0.829 & & & & \\
\hline \multirow{4}{*}{$\begin{array}{l}\text { Serum creatinine } \\
\text { concentration } \\
(\mu \mathrm{mol} / \mathrm{L})\end{array}$} & Carvedilol & $200 \pm 100$ & $210 \pm 100$ & $220 \pm 90$ & $230 \pm 80^{*}$ & $250 \pm 100^{*}$ \\
\hline & ARB & $200 \pm 100$ & $220 \pm 100$ & $250 \pm 110^{*}$ & $250 \pm 100^{*}$ & $260 \pm 100^{*}$ \\
\hline & $\mathrm{CCB}$ & $200 \pm 110$ & $200 \pm 120$ & $220 \pm 120$ & $240 \pm 80 *$ & $250 \pm 100^{*}$ \\
\hline & $\mathrm{P}^{\dagger}$ & 0.998 & & & & \\
\hline \multirow{4}{*}{$\begin{array}{l}\text { Estimated glomerular } \\
\text { filtration rate } \\
\left(\mathrm{mL} / \mathrm{min} / 1.73 \mathrm{~m}^{2}\right)\end{array}$} & Carvedilol & $32.7 \pm 16.5$ & $32.8 \pm 18.5$ & $29.3 \pm 13.1$ & $26.4 \pm 13.1^{*}$ & $25.7 \pm 11.7^{*}$ \\
\hline & ARB & $35.2 \pm 17.3$ & $32.5 \pm 16.7$ & $28.4 \pm 17.8^{*}$ & $27.3 \pm 16.5^{*}$ & $26.5 \pm 14.1^{*}$ \\
\hline & CCB & $35.4 \pm 18.5$ & $35.7 \pm 18.7$ & $33.0 \pm 16.3$ & $25.3 \pm 9.9^{*}$ & $25.1 \pm 11.1^{*}$ \\
\hline & $\mathrm{P}^{\dagger}$ & 0.805 & & & & \\
\hline \multirow{4}{*}{$\begin{array}{l}\text { Urinary } \\
\text { albumin/creatinine } \\
\text { ( } \mu \mathrm{g} / \mathrm{g} \text { creatinine) }\end{array}$} & Carvedilol & $832 \pm 353$ & $877 \pm 444$ & $822 \pm 395$ & $933 \pm 481$ & $791 \pm 404$ \\
\hline & $\mathrm{ARB}$ & $960 \pm 481$ & $1111 \pm 774$ & $738 \pm 420^{*}$ & $844 \pm 466$ & $668 \pm 376^{*}$ \\
\hline & CCB & $801 \pm 506$ & $767 \pm 457$ & $707 \pm 589$ & $757 \pm 525$ & $690 \pm 590$ \\
\hline & $\mathrm{P}^{\dagger}$ & 0.353 & & & & \\
\hline
\end{tabular}

${ }^{*} P<0.05,{ }^{* *} P<0.01$ compared with the value at the start of study ( 0 week) in each group. $\mathrm{P}^{\dagger}$, comparison among three groups at 0 week. ARB; angiotensin II receptor blockers, CCB; calcium channel blockers

an increase in serum creatinine concentration (Table 3). However, after 24 weeks, the other two groups also showed significant decreases in eGFR. Urinary albumin/creatinine ratio decreased only in the ARB group at 12 and 48 weeks. However, in this group, serum potassium level began to increase from 4 weeks onwards, requiring cation-exchange resins in 10 patients, compared with 4 patients in the carvedilol group $(\mathrm{P}=0.039)$ and 3 patients in the CCB group. Finally all three groups showed elevated serum potassium levels at 48 weeks.

\section{Glucose metabolism and HOMA-IR}

There were no significant differences in baseline fasting serum glucose level, insulin level and hemoglobin A1c among the three groups, and no significant changes of the indices during the study period in each group (Table 4). HOMA-IR also showed no significant changes during the study period in the three groups (Table 4).

\section{Adverse reactions}

There was no withdrawal due to hypotension or anemia while patients were on combination therapy. No hypoglycemic attack occurred in the three groups. Fifteen patients in the CCB group showed leg edema, whereas six patients in the carvedilol group and nine patients in the ARB group had edema $(\mathrm{P}=0.056)$.

\section{Discussion}

In the present study, ARB decreased BP gently with increasing doses. However, the rate of achieving the therapeutic goal was still not high, and more patients showed further impairment of renal function. Serum potassium levels rose with increased ARB doses. Consequently, compared to the other two groups, more patients needed to take cationexchange resins for hyperkalemia. Thus, although RAS inhibitors are the first line agents for hypertensive patients with CKD $[8,9]$, when using ARB in patients with severe renal failure, careful dose adjustment is necessary. Otherwise adverse effects will develop easily. 


\section{Kidney \\ Blood Pressure Research}

Yasuda/Yatsu/Yamamoto/Hirawa: Effects of Carvedilol as Third-Line Add-On Therapy on Blood Pressure in Diabetic Patients

Table 4: Glucose metabolism during treatment for 48 weeks in each group

\begin{tabular}{|c|c|c|c|c|c|c|c|}
\hline \multirow{2}{*}{ Parameter } & \multirow{2}{*}{ Group } & \multicolumn{6}{|c|}{ Duration of treatment (weeks) } \\
\hline & & 0 & 4 & 12 & 24 & 48 & $P$ \\
\hline \multirow{4}{*}{$\begin{array}{l}\text { Fasting serum glucose } \\
\text { concentration (mmol/L) }\end{array}$} & Carvedilol & $6.8 \pm 1.9$ & $7.1 \pm 2.4$ & $6.9 \pm 1.8$ & $7.7 \pm 2.2$ & $7.4 \pm 2.0$ & 0.426 \\
\hline & $\mathrm{ARB}$ & $7.4 \pm 2.4$ & $6.7 \pm 2.1$ & $7.7 \pm 2.9$ & $7.3 \pm 2.8$ & $7.0 \pm 2.2$ & 0.743 \\
\hline & CCB & $7.1 \pm 2.2$ & $7.0 \pm 2.7$ & $7.9 \pm 2.8$ & $7.8 \pm 2.8$ & $8.1 \pm 3.0$ & 0.389 \\
\hline & $\mathrm{P}^{\dagger}$ & 0.607 & & & & & \\
\hline \multirow[t]{4}{*}{ Hemoglobin A1c (\%) } & Carvedilol & $6.5 \pm 1.3$ & $6.5 \pm 1.3$ & $6.5 \pm 1.2$ & $6.3 \pm 1.3$ & $6.2 \pm 1.2$ & 0.889 \\
\hline & $\mathrm{ARB}$ & $6.6 \pm 1.1$ & $6.5 \pm 1.2$ & $6.6 \pm 1.1$ & $6.7 \pm 1.8$ & $6.5 \pm 1.2$ & 0.905 \\
\hline & $\mathrm{CCB}$ & $6.6 \pm 1.1$ & $6.4 \pm 1.1$ & $6.6 \pm 1.1$ & $6.1 \pm 1.8$ & $6.3 \pm 1.1$ & 0.418 \\
\hline & $\mathrm{P}^{\dagger}$ & 0.581 & & & & & \\
\hline \multirow{4}{*}{$\begin{array}{l}\text { Serum insulin concen- } \\
\text { tration (pmol/L) }\end{array}$} & Carvedilol & $65 \pm 60$ & $70 \pm 60$ & $55 \pm 35$ & $60 \pm 40$ & $70 \pm 65$ & 0.899 \\
\hline & $\mathrm{ARB}$ & $70 \pm 70$ & $75 \pm 45$ & $70 \pm 35$ & $65 \pm 40$ & $80 \pm 50$ & 0.905 \\
\hline & ССВ & $65 \pm 65$ & $65 \pm 45$ & $75 \pm 45$ & $60 \pm 45$ & $70 \pm 50$ & 0.889 \\
\hline & $\mathrm{P}^{\dagger}$ & 0.984 & & & & & \\
\hline \multirow[t]{4}{*}{ HOMA-IR } & Carvedilol & $3.1 \pm 3.2$ & $3.1 \pm 3.1$ & $2.3 \pm 1.6$ & $2.6 \pm 1.7$ & $3.1 \pm 3.2$ & 0.352 \\
\hline & $\mathrm{ARB}$ & $3.1 \pm 2.7$ & $2.9 \pm 1.7$ & $3.5 \pm 2.3$ & $2.9 \pm 2.6$ & $3.3 \pm 2.3$ & 0.654 \\
\hline & CCB & $2.9 \pm 2.7$ & $2.7 \pm 1.6$ & $3.6 \pm 2.6$ & $2.9 \pm 2.2$ & $3.3 \pm 2.2$ & 0.270 \\
\hline & $\mathrm{P}^{\dagger}$ & 0.971 & & & & & \\
\hline
\end{tabular}

$\mathrm{P}^{\dagger}$, comparison among three groups at 0 week. ARB; angiotensin II receptor blockers, CCB; calcium channel blockers, HOMA-IR; homeostasis model assessment-insulin resistance

Based on the guidelines $[1,2,10]$, we selected CCB as the second choice for patients in whom BP remained uncontrolled with ARB monotherapy. The present study demonstrated that doubling the dose of CCB decreased BP. However, 58\% of the patients still did not achieve the BP goal. As a result, these patients required additional furosemide not only to decrease BP but also to reduce edema that was probably induced by CCB. Thus, although RAS inhibitors and CCB are currently the most rational choices for treating hypertensive patients with diabetic nephropathy, both drugs may not be given at the highest recommended doses due to the concern of adverse drug reactions. Third-line antihypertensive drug must be taken into consideration.

As the next option for the treatment of hypertension in patients with diabetic nephropathy and advanced renal insufficiency, furosemide is recommended to reduce hydration and edema, but this agent is short acting and not effective for BP control. Besides, furosemide has adverse effects on lipid and glucose metabolism as well as uric acid metabolism. Therefore, we did not choose diuretics as the third preferential option for diabetic patients with advanced renal failure. Instead, we chose carvedilol, which has been reported to have unique pharmacological effects including lower risk of causing new onset diabetes [11] and inhibition of oxidative stress [12]. Carvedilol also produces peripheral vasodilation caused by $\alpha_{1}$ adrenergic blockade, facilitating glucose uptake by muscle cells [13]. These factors raise a possibility that carvedilol may be beneficial for BP control and organ protection in patients with diabetes and advanced renal failure.

In the present study, the efficacy of decreasing BP to the therapeutic goal was not different among three groups. Further, there were no changes in glucose metabolism and insulin resistance in the three groups. These results infer that carvedilol did not deteriorate glucose metabolism and insulin resistance [14]. On the other hand, increasing ARB doses to regulate BP (ARB group) was accompanied by higher incidence of hyperkalemia and deterioration of renal function than the other two groups. Our study showed the similar rates of deterioration of renal function in the CCB and carvedilol groups. Therefore, adding carvedilol or increasing CCB doses should be the third-line treatment.

Many clinical trials have provided evidence that a combination of CCB and RAS inhibitors confers renoprotective effects [15]. Meanwhile, a combination of $\beta$-blocker and RAS inhibitor 


\section{Kidney \\ Blood Pressure Research}

Kidney Blood Press Res 2012;36:131-138

\begin{tabular}{l|l}
\hline DOI: $10.1159 / 000341491$ & C 2012 S. Karger AG, Basel
\end{tabular}

Published online: October 23, 2012

www.karger.com/kbr

Yasuda/Yatsu/Yamamoto/Hirawa: Effects of Carvedilol as Third-Line Add-On Therapy on Blood Pressure in Diabetic Patients

has been shown to be more effective in decreasing BP than high-dose monotherapy [16]. The European Society of Hypertension recommends a combination of $\beta$-blockers and CCB as one of two combination treatment options [2]. Thus, carvedilol should be another option to slow the deterioration of organ damage caused by hypertension in patients with advanced renal failure in whom ARB and CCB combined therapy is not fully efficient. If there are limitations to increase ARB and CCB doses due to intolerance or serious adverse effects during longstanding therapy, adding carvedilol as a third agent should be more useful than increasing the doses of the first- and second-line agents.

Some limitations to the study need to be mentioned. We have evaluated clinic BP in diabetic patients with CKD. However, those patients must have elevated nighttime BP which is more associated with hypertensive target-organ damage. In such patients, ambulatory BP monitoring has proved to be more reliable modality than the single office BP readings for evaluating and comparing the efficacies of antihypertensive drugs.

\section{Conclusion}

The present findings suggest that carvedilol, as the combination therapy with ARB and CCB, can be used safely and effectively for hypertension treatment in patients with advanced diabetic nephropathy. However, the rate of achieving the therapeutic BP goal is still low. Thus, further studies with a large number of patients and long-term observation using ambulatory $\mathrm{BP}$ monitoring are necessary to find the optimal dosage of carvedilol used in combination with ARB and CCB.

\section{References}

1 National Institute for Health and Clinical Excellence. Hypertension: Clinical management of primary hypertension in adults. NICE clinical guideline 127, 2011. http://guidance.nice.org.uk/CG127/Guidance/ pdf/English.

-2 Mancia G, De Backer G, Dominiczak A, Cifkova R, Fagard R, Germano G, Grassi G, Heagerty AM, Kjeldsen SE, Laurent S, Narkiewicz K, Ruilope L, Rynkiewicz A, Schmieder RE, Struijker Boudier HA, Zanchetti A, Vahanian A, Camm J, De Caterina R, Dean V, Dickstein K, Filippatos G, Funck-Brentano C, Hellemans I, Kristensen SD, McGregor K, Sechtem U, Silber S, Tendera M, Widimsky P, Zamorano JL, Kjeldsen SE, Erdine S, Narkiewicz K, Kiowski W, Agabiti-Rosei E, Ambrosioni E, Cifkova R, Dominiczak A, Fagard R, Heagerty AM, Laurent S, Lindholm LH, Mancia G, Manolis A, Nilsson PM, Redon J, Schmieder RE, Struijker-Boudier HA, Viigimaa M, Filippatos G, Adamopoulos S, Agabiti-Rosei E, Ambrosioni E, Bertomeu V, Clement D, Erdine S, Farsang C, Gaita D, Kiowski W, Lip G, Mallion JM, Manolis AJ, Nilsson PM, O'Brien E, Ponikowski P, Redon J, Ruschitzka F, Tamargo J, van Zwieten P, Viigimaa M, Waeber B, Williams B, Zamorano JL: 2007 Guidelines for the management of arterial hypertension. Eur Heart J 2007;28:1462-1536.

-3 Ohkubo T, Obara T, Funahashi J, Kikuya M, Asayama K, Metoki H, Oikawa T, Takahashi H, Hashimoto J, Totsune K, Imai Y: Control of blood pressure as measured at home and office, and comparison with physicians' assessment of control among treated hypertensive patients in Japan: First report of the Japan home versus office blood pressure measurement evaluation (J-HOME) study. Hypertens Res 2004;27:755763.

4 Bakris GL, Fonseca V, Katholi RE, McGill JB, Messerli FH, Phillips RA, Raskin P, Wright JT Jr, Oakes R, Lukas MA, Anderson KM, Bell DS: Metabolic effects of carvedilol vs metoprolol in patients with type 2 diabetes mellitus and hypertension. JAMA 2004;292:2227-2236. 


\section{Kidney \\ Blood Pressure Research}

Kidney Blood Press Res 2012;36:131-138

\begin{tabular}{l|l}
\hline DOI: 10.1159/000341491 & (C) 2012 S. Karger AG, Basel
\end{tabular}

Published online: October 23, 2012

www.karger.com/kbr

Yasuda/Yatsu/Yamamoto/Hirawa: Effects of Carvedilol as Third-Line Add-On Therapy on Blood Pressure in Diabetic Patients

5 Takizawa T, Tochikubo 0, Miyajima A, Yasuda G, Ishii M: Effects of carvedilol on 24-hour blood pressure monitored by a new multibiomedical recorder. Ther Res (Japan) 1997;18:2655-2663.

6 Haffner SM, Gonzalez C, Miettinen H, Kennedy E, Stern MP: A prospective analysis of the HOMA model. Diabetes Care 1996;19:1138-1141.

7 Matsuo S, Imai E, Horio M, Yasuda Y, Tomita K, Nitta K, Yamagata K, Tomino Y, Yokoyama H, Hishida A: Revised equations for estimated GFR from serum creatinine in Japan. Am J Kidney Dis 2009;53:982-992.

-8 Yasuda G, Kuji T, Hasegawa K, Hirawa N, Kihara M, Toya Y, Shionoiri H, Umemura S: Safety and efficacy of a biliary-excreted angiotensin converting enzyme (ACE) inhibitor, temocapril, in combination with amlodipine in advanced diabetic nephropathy. Clin Exp Nephrol 2002;6:229-236.

-9 Douglas JG, Agodoa L: ACE inhibition is effective and renoprotective in hypertensive nephrosclerosis: the African American Study of Kidney Disease and Hypertension (AASK) trial. Kidney Int 2003;83:S74-S76.

$>10$ Chobanian AV, Bakris GL, Black HR, Cushman WC, Green LA, Izzo JL Jr, Jones DW, Materson BJ, Oparil S, Wright JT Jr, Roccella EJ: Seventh report of the joint national committee on prevention, detection, evaluation, and treatment of high blood pressure. Hypertension 2003;42:1206-1252.

-11 Torp-Pedersen C, Metra M, Charlesworth A, Spark P, Lukas MA, Poole-Wilson PA, Swedberg K, Cleland JG, Di Lenarda A, Remme WJ, Scherhag A: Effects of metoprolol and carvedilol on pre-existing and new onset diabetes in patients with chronic heart failure: data from the Carvedilol Or Metoprolol European Trial (COMET). Heart 2007;93:968-973.

12 Yasunari K, Maeda K, Nakamura M, Watanabe T, Yoshikawa J, Asada A: Effects of carvedilol on oxidative stress in polymorphonuclear and mononuclear cells in patients with essential hypertension. Am J Med 2004;116:460-465.

-13 Sander GE, Giles TD: Thiazide diuretics and ß-blockers in the treatment of hypertension in diabetes mellitus. J Clin Hypertens 2011;13:296-300.

14 Jacob S, Rett K, Henriksen EJ: Antihypertensive therapy and insulin sensitivity: Do we have to redefine the role of ß-blocking agents? Am J Hypertens 1998;11:1258-1265.

-15 Matsuzaki M, Ogihara T, Umemoto S, Rakugi H, Matsuoka H, Shimada K, Abe K, Suzuki N, Eto T, Higaki J, Ito S, Kamiya A, Kikuchi K, Suzuki H, Tei C, Ohashi Y, Saruta T: Prevention of cardiovascular events with calcium channel blocker-based combination therapies in patients with hypertension: a randomized controlled trial. J Hypertens 2011;29:1649-1659.

16 Bakris GL, Iyengar M, Lukas MA, Ordronneau P, Weber MA: Effect of combining extended-release carvedilol and lisinopril in hypertension: Results of the COSMOS study. J Clin Hypertens 2010;12:678-686. 